\title{
Linguistic nationalism in early-colonial Assam: The American Baptist Mission and Orunodoi
}

\author{
Arnab Dasgupta \\ Asst. Professor, Hansraj College, University of Delhi, ORCID ID: oooo-ooo2-3394-4564. \\ Email:adasgupta@hrc.du.ac.in
}

\begin{abstract}
This paper will attempt to map the emergence of linguistic nationalism as a direct offshoot of the language debate in early-colonial Assam. In 1836, Bengali was made the language of courts and schools in Assam. Ten years later, the Baptist Mission at Sadiya started publishing a monthly magazine called Orunodoi. Orunodoi gradually became a critical instrument in the effort to reinstate Assamese as the language of the province's courts and schools. How did the emergent public sphere react to the debate on language? What was the power dynamic between an emergent native intelligentsia, the Baptist Mission and the colonial state in earlycolonial Assam? What are the factors that prevented Assamese from being reinstated as the language of courts and schools in Assam until 1873? Was the debate on language merely about imposition of a 'foreign' language, or was the discourse more fluid with concerns like language standardisation operating as undercurrents? Can the language debate in early-colonial Assam be isolated as the first assertion of a sub-national identity based upon cultural and linguistic 'uniqueness'? Through an analysis of some articles published in Orunodoi, read along with private letters and official correspondences of the American Baptist Mission in Assam, this paper will attempt to address some of these questions and recover the context of the debate around language in nineteenth-century Assam.
\end{abstract}

Keywords: Assam, Colonial, Print culture, Linguistic nationalism, American Baptist Mission

The 'age of Orunodoi', spanning roughly between 1846 till about 1889, was a period of political turmoil in Assam. In the course of Orunodoi's career as a monthly magazine published by the American Baptist Mission, the boundary of Assam was redrawn for the second time after 1826, and Assam acquired the status of a province within British India in 1874. Owing to the efforts of individuals like Rev. Miles Bronson, Rev. Nathan Brown, Anandaram Dhekiyal Phukan and Gunabhiram Barua, Assamese was reinstated as the medium of instruction in the Government schools and the language of the Courts in 1873; thirty seven years after it was replaced by Bengali as the language of the province in 1836.

Relying on information from Francis Buchanan Hamilton's An Account of Assam (1814), William Robinson's A Descriptive Account of Assam (1841), Haliram Dhekiyal Phukan's Assam Buranji (1829) and assorted government correspondences, Amalendu Guha in his article titled 'Colonisation of Assam: Years of Transitional Crisis (1825-40)' (1968) concludes that the transitional period from Ahom to British rule was a period of all round economic stagnation in Assam. Maheswar Neog argues that the immediate effect on the masses of the introduction of Bengali in Assam was one of stupefaction. The collapse of the five-hundred-year-old Ahom empire, and the disenfranchisement of an aristocracy that enjoyed unbridled power under the Ahoms, coupled with a period of drastic changes in the economic dynamics of the province created a political ambiguity from which no clear leadership that could rally public opinion emerged. Orunodoi became the

(c) AesthetixMS 2021. This Open Access article is published under a Creative Commons Attribution Non-Commercial 4.0 International License (http://creativecommons.org/licenses/by-nc/4.o/), which permits non-commercial re-use, distribution, and reproduction in any medium, provided the original work is properly cited. For citation use the DOI. For commercial re-use, please contact editor@rupkatha.com. 
platform for rallying public opinion in favour of the Assamese language and the missionaries associated with the American Baptist Mission, notably Nathan Brown and Miles Bronson, were at the vanguard of a movement for the restoration of Assamese.

The colonial language policy in Assam was formulated primarily due to administrative reasons. In a letter written on the $7^{\text {th }}$ of December, 1854 to Sir William Grey, Secretary to the Government of Bengal, Francis Jenkins writes:

When I assumed charge of this office, I found all the omlah with two or three exceptions, of individuals holding inferior situations Bengalis from Sylhet, Mymensing and Dacca, some of these had been under Mr. Scott, but the principal officers who were mostly from Sylhet, had been introduced by Mr. Robertson...[t]he business of the courts was almost entirely conducted in Bengali... (Barpujari, 1986)

It was during the tenure of Francis Jenkins as the Commissioner of Assam that Bengali was introduced as the official language of the province. As is apparent from the letter, it was the overwhelming majority of Bengalis in the administrative services of Assam that was a catalyst for the decision to make Bengali the official language. Maheswar Neog in the introduction to his compiled edition of Orunodoi argues that the British officials who came to Assam carried with them the notion that Assamese was only a patois of Bengali. Therefore, the struggle for Assamese was a struggle to reclaim its position as a language that had an existence independent of Bengali.

The focal point of most studies of language in Assam has been the growth of linguistic nationalism and the role that language played in forging an essentially Assamese identity in nineteenth-century Assam. The nomenclature used to classify this phenomenon of identity assertion has varied from being called 'Assamese sub-nationalism' in the writings of Amalendu Guha to 'Assamese micro-nationalism' in Sanjib Baruah . (Baruah, 1994) As enabling as the term micro-nationalism (or sub-nationalism) might be for any analysis of nationalism in Assamese, this categorisation tends to overlook the fissures within the discourse. In his critical commentary on Orunodoi, Prasenjit Choudhury accurately makes a distinction between 'linguistic nationalism' on the one hand and a more aggressive assertion of Assamese culture and identity on the other. The latter, according to Choudhury, is a late nineteenth century phenomenon which appeared along with the inception of the Asomiya Bhasa Unnati Sadhini Sabha (Society for the Promotion of the Assamese Language) in 1888. It is, however, in the pages of Orunodoi that Choudhury locates the seeds of linguistic nationalism in Assam. Right from 1846, the year of Orunodoi's first appearance until 1858 and even beyond, the pages of the magazine remained the site where the case for Assamese language and its restoration in Assam was articulated.

Orunodoi primarily concerned itself with issues of religion, science and general intelligence. Given its religious orientation, a section on religious intelligence was also a regular feature in the magazine. A letter written on the $4^{\text {th }}$ of July, 1850 by Nathan Brown to Appleton How Danforth, the man who would take over the responsibility of editing Orunodoi from Brown in five years time, leaves no doubt regarding the agenda behind the magazine and more specifically the articles on religion. In the letter, Brown states that:

The Orunodoi has been considered by the mission as one of the most powerful instrumentalities for gaining access to the mind of the Assamese, and nothing we have ever done has created such an interest among them...as did the Orunodoi for the first two or three years. No other instrument that we could use would exert half of the influence in enlightening the native mind and undermining their shaster as a paper of this kind...we found it to succeed beyond our expectation. (Barpujari, 1986) 
However, Prasenjit Choudhury argues citing an article published in the Baptist Missionary Magazine in July 1890 that this euphoria among the Baptists did not last long. This article laments that ' $[t]$ he Missionary work among the Assamese...who are Hindu in religion, cannot be said to have been very successful'. (Choudhury, 1995)

Most nationalist commentaries on Assam have argued that the primary reason for the American Baptists behind starting a magazine like the Orunodoi was the task of protecting and promoting the Assamese language against the growing influence of Bengali. Literary historian Dimbeswar Neog goes to the extent of proclaiming that Orunodoi and Jonaki were nothing but reactions to the attack by Bengali. Choudhury detects similar sentiments across a body of literary histories of Assam written between 1975 and 1991 where the issue of language has been presented as the central concern of Orunodoi. This absolute position becomes untenable because evidence suggests that the question of language was not central in the missionary imagination initially. Choudhury in fact argues that the American Baptists deliberately tried to steer clear of the language policy of the East India Company, possibly the reason why Anandaram Dhekiyal Phukan's treatise titled A Few Remarks on the Assamese Language and on Vernacular Education in Assam (1855) was published with the pseudonym 'A Native' from the Baptist Press in Sibsagar. Language also does not feature as a thrust area in the magazine that was tentatively devoted to 'religion, science and general intelligence'. It is, however, an undeniable fact that after 1854, the pages of Orunodoi did become the site for articulation of various positions on the language policy of the British government.

The possible reason behind this policy shift on the part of the American Baptist Mission whereby they became active participants in the dialectic concerning the issue of language in Assam can be located in Nathan Brown's 1848 work Grammatical Notes on the Assamese Language. Nathan Brown was actively involved in recovering old Assamese manuscripts and preparing books for the education in the Baptist schools since 1838. In this process, he mastered the Assamese language and his introduction to Grammatical Notes on the Assamese Language is perhaps the first expression of the missionary position vis-à-vis the colonial language policy. In the Introduction, Brown clearly states that '[t]he opinion that the present language of Bengal is the parent of Assamese, is irreconcilable with facts'. (Brown, 1848) In a letter to Fredrick James Halliday, the Lieutenant Governor of Bengal, on $13^{\text {th }}$ November 1854 , Miles Bronson squarely blames the decision to make Bengali the official language of Assam for the disadvantages that the American Baptists had to face in Assam. In this letter, Bronson lists out all the developmental work in the field of education that had been accomplished by the American Baptists between 1836 and 1854 . He states that:

We (American Baptists) have established two printing presses, and issued the whole New Testament, portions of the Old Testament, a number of Elementary books for schools, and a monthly paper, all in the vernacular. But in the prosecution of our efforts...one sore discouragement attends us. I refer to the substitution of Bengali for Assamese in all the schools and educational efforts of Government so that instead of being able to bring our own presses and books and schools to active concert with the efforts of Government, we find ourselves far less favorably situated than we had hoped, for effecting immediate and permanent good for this long neglected people. (Barpujari, 1986)

On $25^{\text {th }}$ of May the following year, in a letter written to the Editor of Friend of India, Bronson wrote that '...the Assamese like all other people, have a mother tongue... (and) have just as strong an attachment to their mother tongue as any other people'. (Barpujari, 1986) The arguments of Miles Bronson as well as Nathan Brown for the restitution of Assamese seem to be driven by genuine desire for 'effecting immediate and permanent good' to a 'long neglected people'. However, 
correspondences between some other members of the American Baptist Mission compel us to reconsider the reasons behind this sudden spurt in missionary interest over the question of language around 1854 . In a letter to Miles Bronson on the $30^{\text {th }}$ of October, 1854, Danforth writes:

I believe that as long as the Courts and Schools are in Bengali, there will be the greatest impediment to the education and improvement of the Assamese. If the Missionaries should adopt Bengali as the means of communicating religious truth, everyone would doubt them. (Barpujari, 1986)

Similar sentiments are expressed in a pamphlet published by the Assam Mission of the American Baptist Missionaries from its Sibsagar based press in 1852. The pamphlet states:

Experience shows that attempts to root out the mother tongue and substitute a foreign dialect seldom succeed. The people must hear in their own tongue, the wonderful works of God. Missionaries to the Burmese must use the Burman (sic) language, to the Bengali the Bengali language, and to the people of Assam the Assamese language. (Choudhury, 1995)

Read in conjunction with Danforth's letter, it becomes apparent that Baptist activism for the cause of Assamese had as much to do with ecclesiastical exigencies as with a wish for the betterment of the people.

Whatever their motivations, the missionaries in Assam did energise the movement that was gaining steam in the 1850 os for the replacement of Bengali from Assam, and Orunodoi became a vital instrument towards that end. Another critical moment in the effort to restore Assamese was the visit to Assam by A. J. Moffat Mills, a Judge of the Sadar Dewani Adalat in June 1853. A. H. Danforth was one of the few people whose opinion was sought regarding the state of affairs in Assam and the letter that he sent was a scathing critique of the British language policy. Danforth equated the practice of teaching Bengali to Assamese children in the Government schools with an effort akin to 'creating a love of knowledge in the mind of a stupid English boy by attempting to teach him French before he knew anything of the rudiments of English.' (Moffat Mills, 1980) Danforth suggested that education in Assam should be imparted in the vernacular at the primarily level and Bengali can be introduced towards the completion of the course.

I would have a course in Bengali rendered more extensive and thorough. This seems absolutely necessary as long as the business of the courts is conducted in that language. Besides, the Bengali has so much in common with the Assamese, and the literature of the latter so meagre at present, it seems desirable that the literature of the Bengali should be thrown open to the Assamese. But I would make this the completion rather than the foundation of education. (Moffat Mills, 1980)

Besides Danforth, the other important petition to Moffat Mills was by Anandaram Dhekiyal Phukan. In his report titled 'Observations on the Administration of the Province of Assam' presented in 1853, Phukan offers a systematic critique of the language policy of the British government. His diagnosis of the reason why education in Assam is in a retrograde state points towards the fact that instruction in...schools are imparted in a foreign language viz. the Bengali, which is but imperfectly understood by the teachers themselves, not to speak of the pupils.' (Moffat Mills, 1980) Anandaram Phukan's prescription is similar to Danforth's when he suggests that Bengali should be introduced at the higher levels of education after the student has had a formal grounding in the vernacular.

Hiren Gohain recognises Anandaram's role in the consolidation of what this paper has identified as linguistic nationalism in Assam. According to Gohain, A Few Remarks on the Assamese 
Language and on Vernacular Education in Assam written by Anandaram Dhekiyal Phukan became a historic document for the consolidation of Assamese nationalism. Linguistic nationalism in Assam emerged as a resistance to the impulse of the colonising agency to suppress the indigenous language and culture within the rhetoric of improvement and modernisation. What nascent Assamese nationalism sought, with individuals like Anandaram Dhekiyal Phukan at the helm, was to negotiate a condition where modernity could be attained while retaining its cultural identity. Linguistic nationalism in Assam followed this predictable trajectory and within the decade of the 1850s, there was a discernable explosion of opinions in the pages of Orunodoi regarding the language policy of the British Government. Despite the divergent motivations, this phase saw a growing synergy between the American Baptist missionaries and individuals like Anandaram Dhekiyal Phukan because their ultimate objective was the same: the restoration of Assamese. The missionaries continued with their policy of passive resistance to the Government language policy by opening up of the pages of Orunodoi for the ventilation of popular opinion on the issue of language.

The debate on the issue of language as it appeared in the Orunodoi emphasised on an essential difference between Assamese and Bengali. In a short untitled article on Assamese and Bengali customs published in June 1847 , the anonymous writer highlighted the difference between Assamese and Bengali social practices. The article argued that 'though the Assamese and Bengalis are of the same religion, their manners and customs are not the same. There are caste Hindus in both the provinces; but the acts that might effect a downgrading of the caste of a Bengali are performed by the Assamese regularly'. (Neog, 1983) The article sought to portray Assam as a liberal space where the malice of caste is largely inconsequential. The piece ends with a declaration that 'be it a Brahmin or a Kalita or a Koch or Kewt or Dom, no section of society is barred from pursuing any profession; a practice that is perhaps better than that of the Bengali Hindus.' This article performs the dual function of iterating the liberal nature of Assamese society, thereby partially negating the colonial rationale of the necessity of improvement of morals through missionary activity in Assam, while at the same time emphasising an essential difference between the social practices of the Assamese and the Bengali. One can isolate a sustained process of the textual construction of the Bengali as the 'other', from the pages of Orunodoi till early twentieth century, when Assamese nationalism takes a more concrete shape. Between 1847 and 1854, Orunodoi remains largely silent on the questions of language and identity, barring occasional pieces that were largely polemical. But with the publication of an article titled 'On the Assamese Language' in the February 1854 issue of the magazine, an organised attempt on the part of the readers and subscribers of Orunodoi to present their point of view vis-à-vis the question of language in Assam becomes evident. 'On the Assamese Language' charts the trajectory of the development of Assamese from Sanskrit. After having spoken at length about the illustrious history of Sanskrit, the anonymous writer declares that '[i]t is beyond doubt that Assamese is a derivation from the Sanskrit language'. (Neog, 1983) The writer dismisses any suggestion that Assamese might have been derived from Bengali. However, unlike the short article on Assamese and Bengali customs that has already been discussed in this paper, this article relies more on rational argument than rhetoric while establishing its claim.

Some people are of the opinion that Assamese has been derived from Bengali. Nothing could be further from the truth. If there are any similarities between these two languages, it is only because of their common origins. Similarities of the Assamese language can be seen not only with Bengali but also with Oriya, the language spoken in a country on the other side of Bengal. (Neog, 1983) 
The comparison with Oriya locates the language debate within the discourse of language change and language development, and thereby outside the realm of speculation and rhetoric. This article also appends a list of words in Assamese, Bengali and Oriya which elaborates the central concern of the article; a lack of scientific approach towards the study of language. That is exactly what this article attempts. The writer argues that Assamese not only displays a close linguistic affinity to Bengali and Oriya but also to some of the dialects spoken by the various hill tribes in and around Assam.

If one were to argue that Bengali is the origin of Assamese language, then by noticing the similarities between Assamese and Oriya, one can also argue that Assamese has been derived from Oriya. If the argument veers towards the issue of relative proximity between Bengal and Assam aiding derivation of Assamese from Bengali, then my response would be that there is no ground for such arguments. It is not only Sanskrit which influenced the Assamese language but also the other dialects that are spoken in the areas around Assam. The hill tribes that abound the hills around Assam have influenced the languageheavily. (Neog, 1983)

What we find in this article is a precise empirical approach to the issue of language change and language development. From 1854, there was an efflorescence of argumentative pieces on the issue of language in Orunodoi. In a December 1855 article titled 'On the Native Language', Purnananda Deka Barua satirises the tendency among a section of the Assamese populace to deride their mother tongue. He states that:

Almost everyone in our country dislikes reading or writing in the local language; they are all too pleased to converse in the foreign Bengali tongue, and also write in the same. Using the Bengali language for conversing with the people of this country ignoring the local dialect is something that can never be appreciated. (Deka Barua, 1855)

This article seeks to infuse a sense of pride for the mother tongue among the Assamese youth which is absolutely essential for forging an Assamese nation based on a common language.

Observe the Sahibs who converse in Bengali, Assamese or Hindustani while interacting with people from those provinces, but whenever he meets his own countrymen, the language that he uses is always English. So, why is the Assamese youth taking great delight in hobnobbing with a foreign language? The youth should seriously consider this question. (Deka Barua, 1855)

Purnanondo Deka Barua has an inclusive approach to the issue of language and asserts that there is no harm in knowing languages of different provinces, but after acquiring Assamese. All that the writer wishes for is a 'reflection on the necessity and value of the national language'. (Neog, 1983) The article lays special emphasis on the fact that Assamese is the national language (dex bhaxa) and that due effort must be made to cultivate the same. Titled 'On the Assamese Language', an article published in the February 1858 issue of the Orunodoi looks closely at problems of comprehension on the part of the natives in the courts of Assam because they do not understand the language in which business is transacted. It is the writer's contention that this lack of grasp over court proceedings because of linguistic barriers is detrimental to the cause of justice.

...because of the prevalence of Bengali in our court proceedings, the people cannot interject, argue or counter argue as they do not understand the language. And when the proceedings are noted, any anomaly resulting out of a lack of comprehension of the language remains unrectified. Later, when the concerned party realises the fault, there is 
absolutely no scope for correction as the amlah simply puts the blame for this error on the person who did not understand the language. (Deka Barua, 1858)

This article cites cases from around the world where local language has suffered because of a premium that is put on languages that are foreign. The writer highlights the poor condition of Bengali when Persian was the language of the court as a precedent of the harmful effects of a foreign language on the development of the vernacular.

When Persian was the official language of Bengal, there was a paucity of good books in Bengali and the language was also unrefined. The people were not as knowledgeable and did not enjoy the comforts they enjoy today. But since the government started endorsing Bengali, the language became beautiful. (Deka Barua, 1858)

This article repeatedly stresses upon the necessity of developing love and respect for the vernacular as a way of reviving an interest in the language. The repeated use of the metaphor of mother tongue (matri bhaxa) while speaking about Assamese and its plight in this article is a clear attempt to forge what Ranajit Guha has called a 'primordial connection that man as species has to natural language'. (Guha, 1998) The writer never accuses the Government overtly of following a discriminatory attitude towards Assamese. Instead, it tries to present the Government's decision of imposing Bengali as a historical necessity owing to a lack of trained workforce within Assam. However, in the light of the changed situation in 1858, the article calls for a re-assessment of the language policy.

...the government in an 1835 order made it compulsory that the language of a province be used for the day to day working of the administration. Because of this Persian was replaced by Bengali in Bengal. But in our country, the British did not find enough trained manpower to execute administrative responsibilities, and hence had to recruit Bengalis to do the job. Maybe that is the reason why the 1835 order was not implemented in Assam. But now, the people of this country have learnt how to work. So, there is no hindrance to local language anymore. (Deka Barua, 1858)

The articles briefly discussed in this paper are representative of a number of other letters and articles that appeared in Orunodoi after 1854 and participated in the debate over the issue of language in Assam. It may be safe to assume that with individuals like Anandaram Dhekiyal Phukan working in tandem with the American Baptist missionaries, the political space was charged with a polyphony of voices expressing their opinion in favour of restoring Assamese in the courts and government schools of Assam. Even Moffat Mills in his 1854 report on the administration of Assam admits a mistake on the part of the Government when he states that '...I think we made a great mistake in directing that all business should be transacted in Bengali, and that the Assamese should acquire it.' (Moffat Mills, 1980)

With a favourable response from a powerful Government emissary like A. J. Moffat Mills, immediate implementation of the recommendations should have followed. However, Bengali was not replaced till $12^{\text {th }}$ of April, 1873; a full nineteen years after Moffat Mills submitted his report. The usual reasons ascribed for this phenomenon are the untimely death of Anandaram Dhekiyal Phukan in 1859, Nathan Brown's dissociation from the Sibsagar mission on the $13^{\text {th }}$ of February 1855 and Bronson's sailing home with his disease stricken family in November 1857. Maheswar Neog has argued that the role of William Robinson was crucial in delaying the return of Assamese. As has already been discussed in this paper, Robinson was in favour of continuing with Bengali as the language of choice for the Government schools in Assam. At the height of the Baptist onslaught demanding that Assamese be made the language of the province, Robinson published a pamphlet titled Some Remarks in Defence of the use of Bengali in the Government School in Assam (1854) where 
he attempted to answer the objections raised by the Baptists and others in favour of Assamese. In this pamphlet, he strongly argues that the language spoken in Assam is 'essentially the same as the Bengali.' (Borpujari, 1986) He alleges that those who maintain that Assamese is a distinct language do so by comparing the colloquial Assamese with the Bengali written in books. Robinson dismisses this method as an invalid test for the uniqueness of Assamese.

...it is, I fear, usual with those who maintain that the Assamese is a language distinct from Bengali, to draw their conclusions from a comparison of the colloquial language of Assam with the refined and elegant Bengali they find in books. This is far from being a correct mode of procedure, and necessarily leads to incorrect results. I have not just now the means of appending a comparative statement of words and phrases in Assamese and any other dialect spoken in Bengal. But could the comparison be made, I have little doubt, that in most instances, even the grammatical forms - in which by the way the only difference exists - will be found to assimilate. (Borpujari, 1986)

This lack of factual evidence in Robinson's article irks A. H. Danforth and in a letter written to Bronson on the $30^{\text {th }}$ of October, 1854, he expresses surprise that 'he (Robinson) should give no facts to sustain his views on a question wherein theories without facts are worth but little'. (Borpujari, 1986) However, it was Bronson's view that the recommendations of Moffat Mills will hold more weight than the opinions of Robinson. When no change in the Government's position could be detected even in 1855 , Robinson wrote a letter to the Editor of Friend of India on the $25^{\text {th }}$ of May where he expressed concerns about the implementation of the proposals of Moffat Mills.

...he (Moffat Mills) recommended that Assamese books be introduced into their schools, and that the Assamese language be the general medium of education - allowing at the same time that the more advanced classes to finish their course with the Bengali if they wished. Will this recommendation of Judge Mills be adopted in the forthcoming scheme? Many are waiting with no small solicitude for the result. (Borpujari, 1986)

The recommendation of Moffat Mills was not adopted till 1873. William Robinson has been systematically charged by historians as being the chief culprit as he in his capacity as the Inspector of Schools ensured that Bengali stayed as the language of the Government schools. However, there were other possible reasons which might have caused a delay in restoring Assamese. The seeds of the problem can be detected in a letter written by an unknown individual to the Editor of the Orunodoi on the $5^{\text {th }}$ of February, 1858. The letter complains that in spite of Orunodoi being the most useful tool for gathering information on Assam, it becomes difficult to understand the content because the language used is not 'plain and simple'. In response, the Editor rejects the allegations, while declaring that the American Baptists 'appreciate the efforts of the learned people of this country who have written...letters pertaining to the standardisation of the Assamese tongue.'

For linguistic nationalists in Assam, the task of standardising the language is of critical importance and the American Baptists were key participants in debates regarding the standard form of Assamese. The idea of standardisation of a vernacular is premised upon an a priori assumption of an authentic and pure language. Such an assumption negates the possibility of language change and language development whereby any change in the imaginary language is deemed as corruption that needs to be purged to arrive at the original language. Recognition of this imagined vernacular linguistic community establishes what Sanghamitra Misra calls a 'hierarchical relationship between what [is] recognised as a standard language and a set of dialects'. (Misra, 2006) Misra argues that the emergence of print culture in Assam was the first step in forging a standardised vernacular in the province. Orunodoi stood at the vanguard of this move towards stabilising the Assamese language at a set standard. The Annual Report of the American Baptist 
Union for the year 1843 debates intensively the question of the most suitable dialect for missionary activity in Assam. The difference in the languages spoken in and around Guwahati as compared with that of Sibsagar was a cause of grave concern for the missionaries. As the report assessed, the 'difference is so great that a missionary speaking only Assamese will not be understood by the people of Lower Assam'. (Borpujari, 1986) Similar apprehensions are apparent in the letter written by Nathan Brown to Solomon Peck, Secretary of the Home Board of the American Baptist Mission on the $22^{\text {nd }}$ of August, 1850 . It is apparent from both the report and the letter that the Baptists preferred the language used in Upper Assam, possibly because that is what they acquired after their advent in Assam. The language used in Orunodoi became the standard language of print and emerged as the 'most potent symbol for forging nationalist identities in the region.' (Misra, 2006) The nationalist discourse in Assam denies that there might have been any resistance to the impulse of language standardisation, the seeds of which can be detected in the pages of Orunodoi. Similarly, the Baptists are celebrated in Assamese nationalist historiography for standing at the vanguard for restoration of Assamese as the language of the courts and schools. However, certain articles written by individuals from within Assam posit a challenge to the conceived role of the missionaries in Assam.

Chandra Mohan Goswami, a teacher in Guwahati High School wrote an article titled 'Remarks on the Assamese Language and on the Propriety of Introducing it into the Courts and Schools in Assam' in 1872 where he criticised the Assamese language as used by the Baptists. While commenting on the work done by the missionaries in Assam, Goswami suggests that however commendable their zeal and laudable their object may be, their labours under a mistaken course have not brought about any beneficial results, neither has their labour been appreciated nor has their language been accepted'. (Goswami, 1872) He further states that 'the language that they (missionaries) are trying to form may serve the purpose of the hewer of wood or the drawer of water, but it cannot satisfy the intellectual wants of the scholar, the philosopher and the poet.' (Goswami, 1872) In the same article, he requests the Government that even if Assamese is restored in Assam, the language of the missionaries should not be considered as standard Assamese. Goswami indicates that the synergy between the educated upper caste Assamese and the American Baptists has resulted in a situation where the missionaries are desirous of leaving a language degraded...whereas the Assamese want to have the dialect of Upper Assam recognised as the language of the whole country.' (Goswami, 1872) The iconic status of Anandaram Dhekiyal Phukan in the history of the resistance movement to the colonial language policy is challenged in this article by Goswami. Referring to Phukan's pamphlet A Few Remarks on the Assamese Language and on Vernacular Education in Assam, Goswami emphasises that '...the pamphlet of Babu Anandoram Phookan is disfigured by fallacious arguments and I am tempted to say by a misrepresentation of facts.' (Goswami, 1872)

The presence of such discordant voices within Assam indicates that the nexus between American Baptist missionaries and the emergent Assamese intelligentsia did not control the discourse of language standardisation in Assam completely. The tendency of nationalist historiography in Assam to silence voices of resistance to the dominant discourse that systematically eulogises the missionaries becomes evident on an analysis of the article by Goswami. Chandra Mohan Goswami actually comes out in support of the Government's action of imposing Bengali on Assam on the ground that at the time of annexation, there were 'as many dialects current in Assam as there were races and districts.' In his view, any other decision would have been unjust because '...preference to the dialect of one class would have given dissatisfaction to the other'. (Goswami, 1872) The American Baptists were aware of the linguistic tensions between the various districts of Assam, as is evident from the Annual Report of the Baptist Mission for the year 1843. In 
an article published in the Assamese periodical Banhi in January 1910 titled 'Axomiya Bhaxa Xombondhe Aru Keitaman Kotha' (A few Words about the Assamese Language), Laxminath Bezbaroa presented the idea that the privileging of the dialect of Sibsagar, the dialect closest to that used by the missionaries is because Sibsagar was the capital of the Ahom kings and the language of the capital becomes the language of the entire kingdom.

Thus, the explosion of letters and articles criticising the stand of the Baptists while undermining the efforts of individuals like Anandaram Dhekiyal Phukan can be analysed as a desperate measure for preventing the standardisation of the Assamese of Upper Assam as the language of Assam by the disgruntled citizens of other parts of the province. This friction between the various linguistic zones within Assam could have been one of the reasons why in spite of Moffat Mills' suggestions, the actual restoration of Assamese took place only in 1873 .

This paper has sought to demonstrate that a seamless, often celebratory, narrativisation of the history of linguistic nationalism in Assam is fraught with methodological and argumentative fallacies. The public sphere in early-colonial Assam was polyphonic, and a systematic negotiation between historical contradictions and intersectional interests of the various parties involved in the debate is critical for any attempt at recovering the contours of the language debate in nineteenthcentury Assam.

\section{References}

Baruah, S. (1994). 'Ethnic' Conflict as State-Society Struggle: The Poetics and Politics of Assamese Micro-Nationalism. Modern Asian Studies, 28(3), 649-671. Retrieved January 30, 2021, from http://www.jstor.org/stable/313047

Barpujari, H. K. (1963). Assam in the Days of the Company (1826-1858). Lawyer's.

Barpujari, H. K. (1986), The American Missionaries and North-East India (1836-190o). Spectrum.

Brown, N. (1848). Grammatical Notes on the Assamese Language. American Baptist Missionary Union.

Choudhury, P. (1995). Orunodoi. Students Stores.

Deka Barua, P. (1855) On the Native Language. Orunodoi 10(12)

Deka Barua, P. (1858) On the Assamese Language. Orunodoi 13(2)

Gohain, H. (1973). Origins of the Assamese Middle Class. Social Scientist, 2(1), 11-26. doi:10.2307/3516465

Goswami, C. M. (1872). Remarks on the Assamese Language and on the Propriety of Introducing it into the Courts and Schools in Assam. (Vol. 59, Transcript No. 17) Directorate of Historical and Antiquarian Studies (Govt. of Assam), Guwahati, Assam.

Guha, R. (1998). Dominance without Hegemony: History and Power in Colonial India. OUP.

Guha, A. (1968). Colonisation of Assam: Years of Transitional Crisis (1825-40). The Indian Economic $\mathcal{E}$ Social History Review, 5(2), 125-140. https://doi.org/10.1177/001946466800500202

Guha, A. (1972). Impact of Bengal Renaissance On Assam: 1325-1875. The Indian Economic E Social History Review, 9(3), 288-304. https://doi.org/10.1177/o01946467200900303

Guha. A. (1977). Planter -Raj to Swaraj Freedon struggle and Electoral Politics in Assam. ICHR.

Misra, S. (2006). Redrawing frontiers: Language, resistance and the imagining of a Goalparia people. The Indian Economic \& Social History Review, 43(2), 199-225 https://doi.org/10.1177/001946460604300203 
Moffat Mills, A. J. (1980) Report on Assam. Gian Publication.

Neog, M. (Ed.). (1983). Orunodoi (1846-1854). Assam Prakashan Parishad.

Neog, D. (1964). Notun Puhorot Axomiya Xahityar Buronji. Xuoni Prakash.

Robinson, W. (1849). Notes on the Languages spoken by the various tribes inhabiting the valley of Assam and its mountain confines. Journal of Asiatic Society, Bengal., xviii, 183-237.

Arnab Dasgupta teaches English at Hansraj College, University of Delhi. His areas of interest include the novel form in India, colonial historiography, and print cultures in early-colonial Assam. He is currently working on nostalgia and urban spaces in post-colonial India. 